\title{
Differential Effect of DCA Treatment on the Pyruvate Dehydrogenase Complex in Patients with Severe PDHC Deficiency
}

\author{
FRANÇOISE FOUQUE, MICHELLE BRIVET, AUDREY BOUTRON, CHRISTIANE VEQUAUD, \\ CÉCILE MARSAC, MARIE-THÉRĖSE ZABOT, AND CHANTAL BENELLI \\ Unité de Recherche Mixte INSERM U530-Université Paris 5, Centre Universitaire des Saints-Pères [F.F., \\ C.B.], and Biochimie, Hôpital Kremlin-Bicêtre [M.B., A.B., C.V.], Paris, France; and CERTO, Hôpital \\ Necker-Enfants Malades [C.M.], and Unité de Biotechnologie, Hôpital Debrousse [M.-T.Z.], \\ Lyon, France.
}

\begin{abstract}
ABST
Dichloroacetate (DCA) is a structural analog of pyruvate that
has been recommended for the treatment of primary lactic aci-
demia, particularly in patients with pyruvate dehydrogenase
(PDHC) deficiency. Recent reports have demonstrated that the
response to DCA may depend on the type of molecular abnor-
mality. In this study, we investigated the response to DCA in
various PDHC-deficient cell lines and tried to determine the
mechanism involved. The effect of chronic 3-d DCA treatment
on PDHC activity was assessed in two PDHC-deficient cell lines,
each with a different point mutation in the E1 $\alpha$ subunit gene
(R378C and R88C), and one cell line in which an 8 -bp tandem
repeat was deleted (W383 del). Only two (R378C and R88C) of
the three PDHC-deficient cell lines with very low levels of
PDHC activity and unstable polypeptides were sensitive to
chronic DCA treatment. In these cell lines, DCA treatment
resulted in an increase in PDHC activity by 125 and 70\%,
\end{abstract}
PDHC deficiency is a nuclear-encoded mitochondrial disorder and a major recognized cause of neonatal encephalopathies associated with primary lactic acidosis (1). This multienzyme complex plays an important role in the irreversible oxidative decarboxylation of pyruvate to acetyl-CoA. E1, one of the subunits of the complex, is a thiamine pyrophosphatedependent pyruvate decarboxylase. It is a tetramer composed of two $\alpha$ and two $\beta$ subunits, the $\alpha$ subunit containing the thiamine pyrophosphate binding sites. E2 is a dihydrolipoamide acetyl transferase. E3 is a dihydrolipoamide dehydrogenase, and $\mathrm{E} 3 \mathrm{BP}$ or protein $\mathrm{X}$ mediates the interaction between E2 and E3. Two elements regulate the complex: an E1 kinase

Received September 27, 2001; accepted November 29, 2002.

Correspondence: C. Benelli, M.D., UMR-S 530 INSERM-Université Paris 5, Centre Universitaire-UFR Biomédicale, 45 rue des Saints-Pères, 75270 Paris, Cedex 06, France; e-mail: benelli@biomedicale.univ-paris5.fr

Supported by grants from Association Française Contre les Myopathies and by the European Commission, contract no. QL G2-CT-1999-00660.

DOI: 10.1203/01.PDR.0000057987.46622.64 respectively, with concomitant increases of 121 and $130 \%$ in steady-state levels of immunoreactive $\mathrm{E} 1 \alpha$. DCA treatment reduced the turnover of the $\mathrm{E} 1 \alpha$ subunit in $\mathrm{R} 378 \mathrm{C}$ and $\mathrm{R} 88 \mathrm{C}$ mutant cells with no significant effect on the E1 $\beta$ subunit. Chronic DCA treatment significantly improved the metabolic function of PDHC in digitonin-permeabilized R378C and R88C fibroblasts. The occurrence of DCA-sensitive mutations suggests that DCA treatment is potentially useful as an adjuvant to ketogenic and vitamin treatment in PDHC-deficient patients.

(Pediatr Res 53: 793-799, 2003)

Abbreviations
DCA, dichloroacetic acid
PDHC, pyruvate dehydrogenase complex
SSCP, single-strand conformation polymorphism

and a phospho-E1 phosphatase, which phosphorylate and dephosphorylate, respectively, three serine residues in the E1 $\alpha$ subunit, resulting in the deactivation and activation, respectively, of the complex (2).

Defects in the PDHC are frequently attributed to deficiencies in the E1 $\alpha$ component (3), encoded by chromosome $\mathrm{X}$ (Xp22.1-22.2) (4, 5). Considerable phenotypic and allelic heterogeneity has been observed for this defect. Previous studies have reported that a decrease in the stability of the E1 $\alpha$ immunoreactive subunit may contribute to the expression of many E1 $\alpha$ mutations $(6,7)$; very few studies to distinguish mutations that impair polypeptide stability from those impairing catalytic efficiency have been carried out to date (8).

DCA is a structural analog of pyruvate that has been recommended for the treatment of primary lactic acidemia, particularly in patients with respiratory chain disorders or PDHC deficiency (9). The beneficial effects of DCA treatment are thought to arise from an increase in the flux of pyruvate to mitochondria and a decrease in serum lactate levels mediated 
by the stimulation of PDHC, as demonstrated by experiments involving chronic daily supplementation in rats (10). DCA is known to be a potent inhibitor of E1 kinase, locking PDHC in its unphosphorylated, catalytically active form (11). However, DCA treatment has remained controversial because of significant side effects such as reversible peripheral neuropathy, which may limit the long-term use of this drug. Furthermore, in one study, most of the patients treated with DCA presented neurologic deterioration advanced to such a point that no improvement was achieved despite the reversal of lactic acidemia (12)

Recent reports have refocused attention on the potential benefits of chronic DCA treatment in PDHC-deficient patients by demonstrating in vitro that DCA responsiveness may be selective and depend on the type of molecular abnormality. It has been shown that chronic DCA treatment increases maximum extractable PDHC activity in cultured human fibroblasts by reducing degradation of the E1 $\alpha$ subunit (13) and that a similar effect is observed in the fibroblasts of patients harboring mutations affecting the stability of the E1 $\alpha$ subunit (14).

In this study, we aimed to extend these observations to other PDHC-deficient cell lines, to confirm the underlying mechanism of chronic DCA treatment and to determine whether the increase in PDHC residual activity improved the flux of pyruvate oxidation through the PDHC reaction.

\section{METHODS}

Case reports. The clinical and immunoblot findings for patients 1 and 2 have been reported elsewhere (15). The studies were approved by local ethic committees and have been conducted with informed consent of the parents.

Patient 1 was born after a term pregnancy and the delivery was normal. At $50 \mathrm{~d}$ of age, he suffered respiratory arrest attributed to bronchiolitis, followed by a secondary seizure. At the age of $4 \mathrm{mo}$, he was referred for hypotonia, poor contact, feeding problems, and psychomotor retardation. At this time, he had drowsiness, trunk hypotonia, strabismus, severe visual impairment, and generalized areflexia and had developed a seizure disorder. Brain magnetic resonance imaging showed abnormal corpus callosum, ventriculomegaly, and cortical atrophy. Plasma lactate and pyruvate concentrations were high (5 and $0.60 \mathrm{mM}$, respectively) but the lactate to pyruvate ratio was normal $(<10)$. He was treated with thiamine $(50 \mathrm{mg} / \mathrm{kg}$ per day) and a ketogenic diet. General clinical improvement was noted after 6 mo of treatment: he had better contact, no areflexia, and a lower level of hypotonia. However, the patient died unexpectedly at the age of $2 \mathrm{y}$.

Patient 2 was a girl who presented at 7 mo with retarded development, tetraplegia, and microcephaly. Brain magnetic resonance imaging showed dilated ventricles with agenesis of corpus callosum. High lactate levels in plasma and cerebrospinal fluid were found with a normal lactate to pyruvate ratio. The patient was treated with thiamine $(50 \mathrm{mg} / \mathrm{kg}$ per day). She is currently 9 y old and has axial hypotonia, peripheral hypertonia, and severe growth and mental retardation.

Patient 3, a boy, was clinically normal at birth but presented at 30 mo with acute hypotonia and retarded development.
Plasma lactate $(4.5 \mathrm{mM})$ and pyruvate $(0.43 \mathrm{mM})$ concentrations were high but the lactate to pyruvate ratio was normal. The patient recovered on a ketogenic diet with thiamine treatment $(50 \mathrm{mg} / \mathrm{kg}$ per day). He is now 5 years old, and his growth and psychomotor function have improved, but he still has slight hypotonia.

Cell culture and lymphocyte isolation. Fibroblasts from skin biopsies were cultured in Dulbecco's modified Eagle's medium (DMEM; Invitrogen, Carlsbad, CA, U.S.A.) with 10\% FCS, $100 \mathrm{U} / \mathrm{mL}$ penicillin, and $100 \mu \mathrm{g} / \mathrm{mL}$ streptomycin. Incubations were performed with or without $5 \mathrm{mM}$ DCA, which was dissolved in distilled water.

Lymphocytes were isolated on Ficoll gradient as described in (16).

Enzyme activities in disrupted fibroblasts and lymphocytes. Total cell activity was measured in triplicate, using $\left[1-{ }^{14} \mathrm{C}\right]$ pyruvate (PerkinElmer Life Science Products, Boston, MA, U.S.A.) as a substrate, after maximal activation of PDHC by treatment of the cells for $15 \mathrm{~min}$ with $5 \mathrm{mM}$ DCA before PDHC extraction obtained by three freeze-thaw cycles for fibroblasts and by sonication for lymphocytes. The cell lysates were preincubated in $0.5 \mathrm{mM} \mathrm{CaCl}_{2}$ and $10 \mathrm{mM} \mathrm{MgCl}_{2}$ for 10 min at $37^{\circ} \mathrm{C}$ as described in (16). Citrate synthase was determined as previously described (17).

Protein concentration was determined according to the method of Bradford (18), with BSA as the standard.

RNA isolation and SSCP analysis. Total RNA was obtained from the cultured fibroblasts of patients and mothers by extraction with the RNAplus kit (Quantum Probe-9-Biogene, Illkirch, France). Each RNA sample (5 $\mu \mathrm{g}$ ) was reverse-transcribed using a first-strand cDNA synthesis kit (Pharmacia Biotech, Amersham Pharmacia Biotech, Seclay, France) according to the manufacturer's instructions. The entire coding sequence of the E1 $\alpha$ gene was amplified by PCR as six consecutive overlapping fragments, using six sets of primers as previously described (19). SSCP analysis was performed by using $8 \%$ polyacrylamide SSCP gels (acrylamide to bis ratio, 37.5:1) with 5\% glycerol. When fragments with altered migration, suggesting mutations in the gene, were detected, they were purified from the agarose gel with a Qiaquick gel extraction kit (QIAGEN, Qiagen SA, Courtaboeuf, France). PCR products or DNA fragments extracted from agarose were sequenced with commercially available automated equipment (Genome Express, Meylan, France). The mutation is numbered from the first amino acid of the sequence according to Lissens et al. (19).

Western immunoblotting. Fibroblasts or lymphocytes were subjected to SDS-PAGE in a $10 \%$ polyacrylamide gel under reducing conditions (16). Proteins were then electrotransferred onto nitrocellulose membranes and probed with rabbit polyclonal anti-PDHC antibodies (diluted 1/2000). The antiserum was raised against purified pig heart PDHC as described by Geoffroy et al. (16). This antiserum recognizes all subunits of the PDHC. Along the study, different batches of antibodies were used, the capacities of which to recognize the different subunits may differ. Immunoreactive proteins were visualized with Amersham ECL detection reagents and quantified by densitometric analysis with an IMSTAR phosphorimager. The relative densities of the bands are expressed as arbitrary ab- 
sorbance units per unit surface area relative to citrate synthase activity in lysates.

Pulse-chase experiments. Confluent skin fibroblasts in $100-\mathrm{mm}$ diameter dishes were incubated in $10 \mathrm{~mL}$ of methionine-free DMEM (Invitrogen) with 10\% FCS (Invitrogen) for $1 \mathrm{~h}$. The medium was then replaced with $3 \mathrm{~mL}$ of the same medium supplemented with $125 \mu \mathrm{Ci}\left[{ }^{35} \mathrm{~S}\right]$ methionine (PerkinElmer Life Science Products). The cells were incubated for various times ( $30 \mathrm{~min}$ to $6 \mathrm{~h}$ ), rinsed three times with sterile PBS, and chased for 2,18 , or $42 \mathrm{~h}$ in standard culture medium without radioactive methionine.

The cells were rinsed three times with PBS, lysed at $4^{\circ} \mathrm{C}$ with $1 \mathrm{~mL}$ of lysis buffer $[50 \mathrm{mM}$ Tris/ $\mathrm{HCl}(\mathrm{pH} 7.6), 150 \mathrm{mM}$ $\mathrm{NaCl}, 1 \% \mathrm{NP}-40,0.1 \%$ SDS, $1 \%$ sodium deoxycholate, 100 $\mu \mathrm{g} / \mathrm{mL}$ phenylmethylsulfonyl fluoride, $1 \mu \mathrm{g} / \mathrm{mL}$ aprotinin], harvested by scraping, and centrifuged for $45 \mathrm{~min}$ at 15,000 $\times$ $g$. The supernatants were stored at $-20^{\circ} \mathrm{C}$ until used for immunoprecipitation experiments. Total protein levels were determined in the supernatants by the method of Bradford (18).

Each sample (volume corresponding to $0.3 \mathrm{mg}$ protein) was preincubated with $150 \mu \mathrm{L}$ of $10 \%(\mathrm{wt} / \mathrm{vol})$ protein ASepharose (Amersham) for $1 \mathrm{~h}$ at $4^{\circ} \mathrm{C}$. The mixture was centrifuged for 4 min at $10,000 \times g$, and the supernatant incubated with PDHC antibodies $(1 / 250)$ overnight at $4^{\circ} \mathrm{C}$. Protein ASepharose $(150 \mu \mathrm{L}$ at $10 \%)$ was then added, and incubation was continued for $1 \mathrm{~h}$ with constant shaking. Sepharose beads were sedimented in a microfuge for $4 \mathrm{~min}$ and washed four times with $1 \mathrm{~mL}$ of lysis buffer and once with this medium without detergents. Adsorbed proteins were eluted in $40 \mu \mathrm{L}$ of $62.5 \mathrm{mM}$ Tris $/ \mathrm{HCl}$ (pH 6.8), $2 \%$ SDS, $10 \%$ glycerol, $2 \%$ $\beta$-mercaptoethanol, and $0.002 \%$ bromophenol blue by incubation for $15 \mathrm{~min}$ at $65^{\circ} \mathrm{C}$. The eluate was subjected to electrophoresis in a $10 \%$ polyacrylamide gel containing SDS, and the gel was soaked in fluorographic reagent (Amplify; Amersham), dried, and autoradiographed.

Oxidative decarboxylation assays in digitonin-permeabilized fibroblasts. The oxidation rate of $\left[1-{ }^{14} \mathrm{C}\right]$ pyruvate and $\left[1,4-{ }^{14} \mathrm{C}\right]$ succinate were measured radiochemically in digitonin-permeabilized fibroblasts. Monolayers of fibroblasts were plated on the bottom of $25-\mathrm{cm}^{2}$ vertical culture flasks and grown for $48 \mathrm{~h}$ in HAM F10 medium (Invitrogen) with $10 \%$ FCS. In some experiments, the culture medium was supplemented with $5 \mathrm{mM}$ DCA for $3 \mathrm{~d}$ before plating and throughout the 48 -h period of cell culture in the $25-\mathrm{cm}^{2}$ flasks. Cells were incubated with ${ }^{14} \mathrm{C}$-labeled substrates for $45 \mathrm{~min}$ at $37^{\circ} \mathrm{C}$, in 1 $\mathrm{mL}$ of respiratory medium (225 mM mannitol, $25 \mathrm{mM}$ HEPES, $50 \mu \mathrm{M}$ EDTA ( $\mathrm{pH} 7.5$ ), $5 \mathrm{mM}$ potassium phosphate, $3 \mathrm{mM}$ ADP) supplemented with $2 \mathrm{mg} / \mathrm{mL}$ BSA and $20 \mu \mathrm{g} / \mathrm{mL}$ digitonin (20). The production of ${ }^{14} \mathrm{CO}_{2}$ was monitored with concentrations of $1 \mathrm{mM}\left[1-{ }^{14} \mathrm{C}\right]$ pyruvate (in the presence of 10 $\mathrm{mM}$ L-carnitine and $5 \mathrm{mM}$ malonate) or $10 \mathrm{mM}[1,4-$ $\left.{ }^{14} \mathrm{C}\right]$ succinate (21). The ${ }^{14} \mathrm{CO}_{2}$ released was trapped on filter paper soaked in $0.2 \mathrm{~mL}$ of $1 \mathrm{M} \mathrm{KOH}$ and suspended from the cap within each flask.

Statistical analysis. The results are expressed as mean \pm SEM. The nonparametric Mann-Whitney $U$ test for pairwise comparisons was applied because of the number of experiments carried out. Analyses were performed using the Stat-
View 4.5 Non-FPU (Abacus Concepts, 1992-1993, Berkeley, CA, U.S.A.) statistical package for Apple Macintosh computers. A value of $p<0.05$ was considered statistically significant.

\section{RESULTS}

Biochemical and molecular characterization of PDHC in patients. PDHC activities in cultured fibroblast cells were $6-22 \%$ of the mean of controls in patients 1,2 , and 3 (values of $34.5 \pm 7.3,117 \pm 17.0,88.7 \pm 8.4, n=3$; control values, $531 \pm 30 \mathrm{pmol} \cdot \mathrm{min}^{-1} \cdot \mathrm{mg}^{-1}$ protein, $n=25$ ). In fresh lymphocytes, PDHC activities were 1 and $10 \%$ of the mean of controls for patients 1 and 3 , respectively $(10 \pm 0.5$ and $68 \pm$ $2.2 \mathrm{pmol} \cdot \mathrm{min}^{-1} \cdot \mathrm{mg}^{-1}$ protein, $n=3$; control values $754 \pm 18$ $\mathrm{pmol} \cdot \mathrm{min}^{-1} \cdot \mathrm{mg}^{-1}$ protein, $n=35$ ). Immunoblot analysis of lymphocyte and fibroblast homogenates are presented in Figure 1. The E1 $\alpha$ subunit was present in much lower quantities in fibroblasts from patients 1,2 , and 3 than in the respective controls (Fig. 1A). In addition, levels of this subunit differed between cell types: for patients 1 and 3, E1 $\alpha$ levels were low in fibroblasts and undetectable in freshly isolated lymphocytes

\section{$A$}

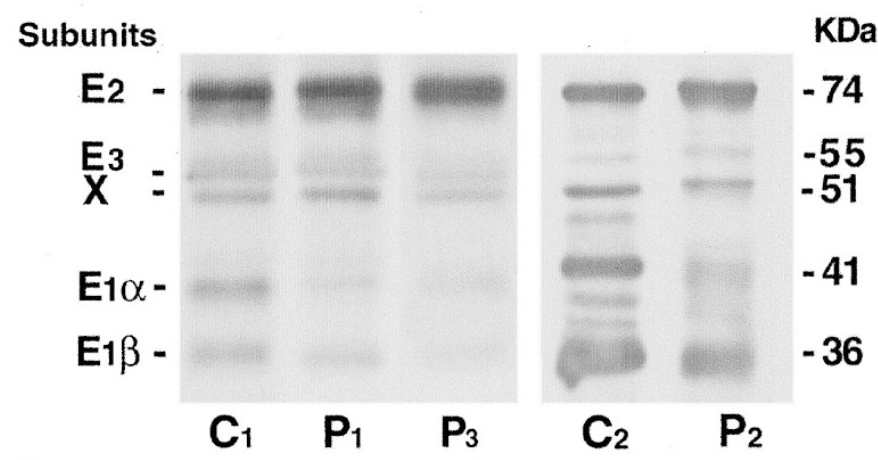

$B$

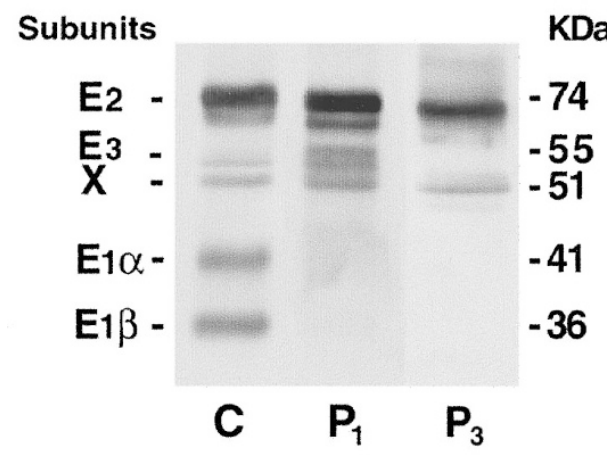

Figure 1. Western blot analysis of fibroblast cell lines $(A)$ and freshly isolated lymphocytes $(B)$ from patients $(P 1, P 2, P 3)$ and controls $(C 1, C 2, C)$ with a polyclonal antibody generated against pig heart PDHC. For fibroblast cell lines, two batches of antibodies were used, one for C1, P1, and P3 and another for $\mathrm{C} 2$ and $\mathrm{P} 2$. Total protein $(5 \mu \mathrm{g})$ from each cell line was solubilized in sample buffer and subjected to SDS-PAGE in a $10 \%$ polyacrylamide gel under reducing conditions. The proteins were then electroblotted onto a nitrocellulose support matrix and probed with antibodies that reacted with all subunits of the purified PDHC. Immunoreactive proteins were detected with electrogenerated chemiluminescence detection. 
(Fig. 1B). No lymphocytes were available from patient 2 for immunoblot studies. Levels of the immunoreactive E1 $\beta$ subunit were also low in fibroblast cell lines from patients 1 and 3 but normal in patient 2 . In lymphocytes from patients 1 and 3 the levels of this subunit were undetectable. E1 $\alpha$ cDNA sequence analysis [this report and (15)] revealed two distinct point mutations in the $\mathrm{E} 1 \alpha$ gene $(\mathrm{R} 378 \mathrm{C}$, and $\mathrm{R} 88 \mathrm{C}$, for patients 1 and 3, respectively) and a deletion of an 8-bp tandem repeat $(\mathrm{W} 383 \mathrm{del})$ in patient 2 . These mutations were not present in the cDNAs isolated from the three mothers.

Chronic DCA treatment and PDHC activity. PDHC activity was 6.5 and $16.7 \%$ in cell lines from patients 1 and 3, respectively, of the mean PDHC in control and reached 14.6 and $28.0 \%$ after a long-term incubation $(3 \mathrm{~d})$ with $5 \mathrm{mM}$ DCA (mean increase in PDHC activity by 125 and $70 \%$ in patients 1 and 3 , respectively). PDHC activity was not modified by the treatment in cell lines from patient 2 (Fig. 2). The increase in activity appeared to be selective for PDHC because citrate synthase activity, a mitochondrial matrix enzyme marker, was unchanged with respect to total cell protein after chronic DCA treatment for all cell lines tested (data not shown).

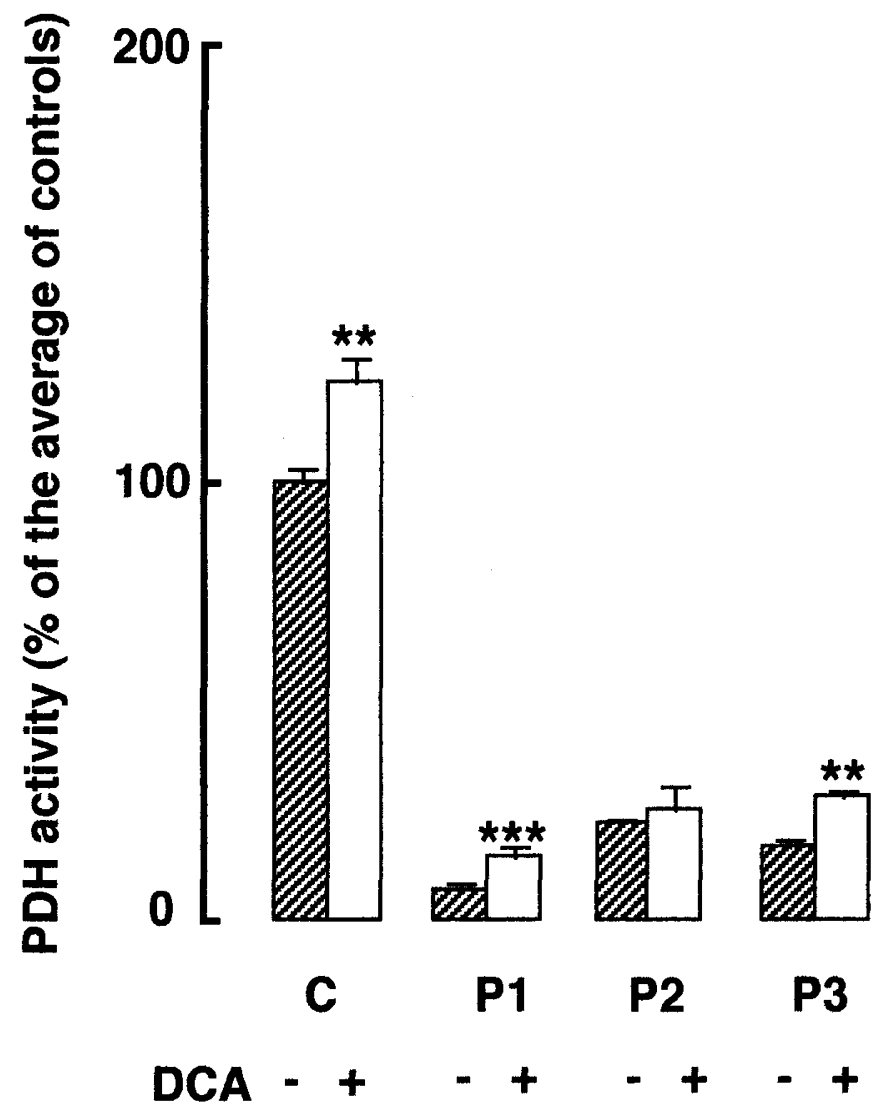

Figure 2. Effect of DCA treatment on total PDHC activity. Human fibroblasts from controls $(C)$ and patients $(P 1, P 2, P 3)$ were cultured in the culture medium with $(\square)$ or without (瓜) $5 \mathrm{mM}$ DCA for $3 \mathrm{~d}$. On d 3, cells were harvested and total PDHC activity was determined. Cells that were cultured without DCA showed no change in PDHC activity during a similar period of study (data not shown). The results ( $n=3-6$ separate cell lines tested) are expressed as percent of PDHC activity of the average controls. PDHC activity for controls was $531 \pm 30 \mathrm{pmol} \mathrm{CO}{ }_{2} \cdot \min ^{-1} \cdot \mathrm{mg}$ protein ${ }^{-1}(n=12$ separate cell lines tested). Asterisks indicate results significantly different from those for untreated cells. ${ }^{*} p<0.05 ;{ }^{* *} p<0.02 ;{ }^{* * *} p<0.005$.
Chronic DCA treatment and steady-state level of immunoreactive $E 1 \alpha$ and $\beta$ subunits. To determine whether the increase in PDHC activity after chronic DCA treatment reflected an increase in PDHC quantity, Western blot analysis was performed (Fig. 3A). We studied the cell lines from patients 1 and 3 because these lines showed the largest increase in PDHC activity after DCA treatment. Immunoblotting of the total cell protein showed that DCA treatment significantly increased, by 121 and $130 \%$, the steady-state immunoreactive E1 $\alpha$ levels relative to E2 levels in PDHC-deficient cell lines from patients 1 and 3, respectively (Fig. 3B). The steady-state

\section{$\boldsymbol{A}$}

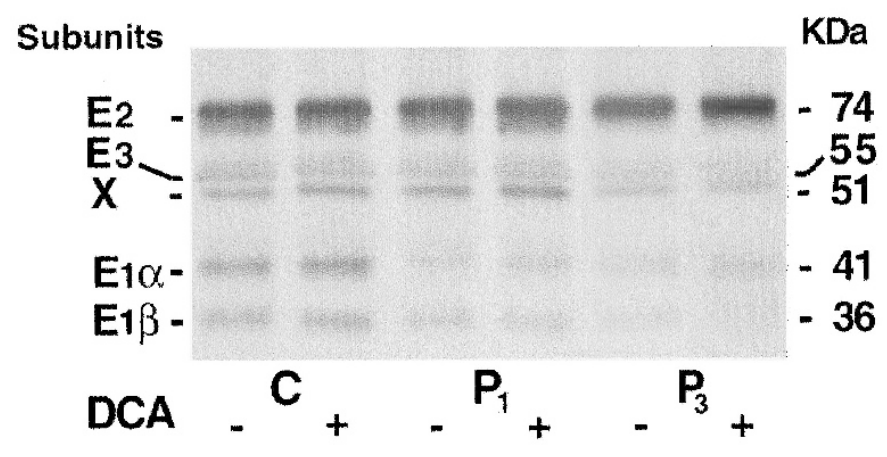

B

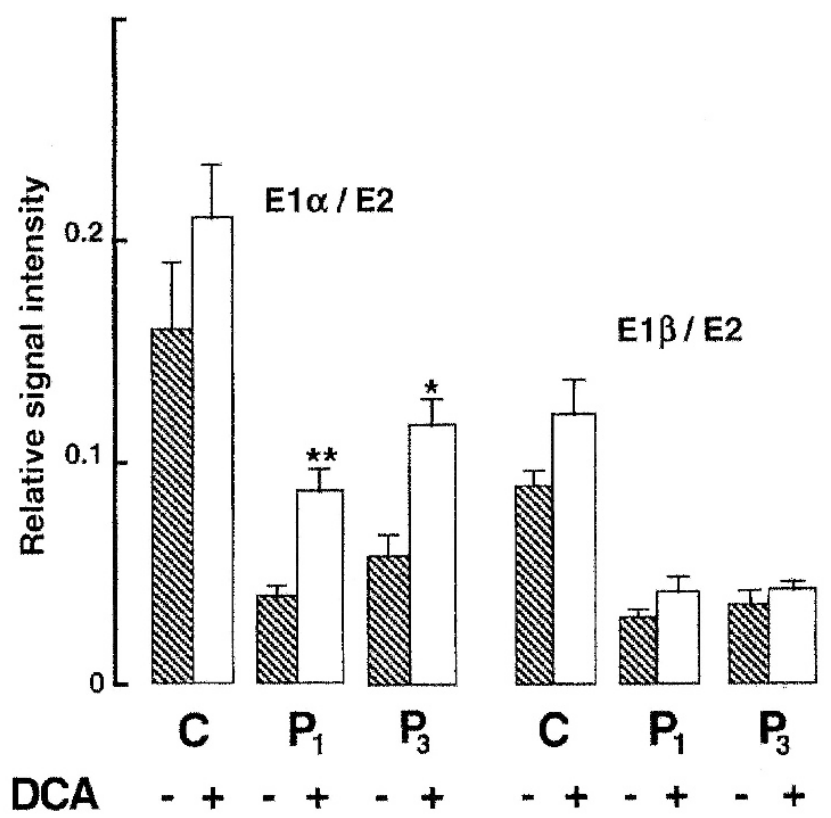

Figure 3. Western blot analysis of PDHC subunit proteins from deficient fibroblast cell lines P1 and P3 and from the control: effect of DCA treatment. $A$, representative experiment with $5 \mu \mathrm{g}$ of protein, corresponding to $644 \pm 22$ $\mu \mathrm{U}$ of citrate synthase for each lane. $B$, relative quantitative analysis of immunoreactive PDHC E1 $\alpha$ and $\beta$ subunits in fibroblast cell lines from C, P1, and P3 with $(\square)$ or without $(\mathbb{\mathbb { Q }})$ DCA. The results are expressed as relative to E2 subunit levels, mean \pm SEM of 4-6 determinations for each condition. Levels of immunoreactive E2 expressed in arbitrary units/unit of citrate synthase were not significantly changed by DCA treatment. Asterisks indicate results significantly different from those for untreated cells. ${ }^{*} p<0.05$; ** $p<$ 0.01 . 
levels of the other immunodetectable subunits (E2 and protein $\mathrm{X})$ relative to citrate synthase activity were not affected by chronic DCA treatment. Levels of immunodetectable E1 $\beta$ subunit were not significantly increased by DCA treatment. In control cells, no significant differences for steady-state levels of either subunit were observed.

Chronic DCA treatment and biosynthesis and turnover of E1 $\boldsymbol{\alpha}$ and $\boldsymbol{\beta}$ subunits. To investigate the effect of DCA treatment on the cellular metabolism of PDHC components, fibroblast cells from a control and from patients 1 (R378C) and 3 (R88C) were metabolically labeled with $\left[{ }^{35} \mathrm{~S}\right]$ methionine, and $\mathrm{PDHC}$ was recovered from lysates by immunoprecipitation with anti-PDHC antibodies (Fig. 4).

The cells were pulse-labeled from $30 \mathrm{~min}$ to $6 \mathrm{~h}$; radiolabeled PDHC components were clearly detectable (Fig. $4 A$ ) as 74-kD (E2), 55-kD (E3), 51-kD (protein X), 41-kD (E1 $\alpha$ ), and

$\boldsymbol{A}$

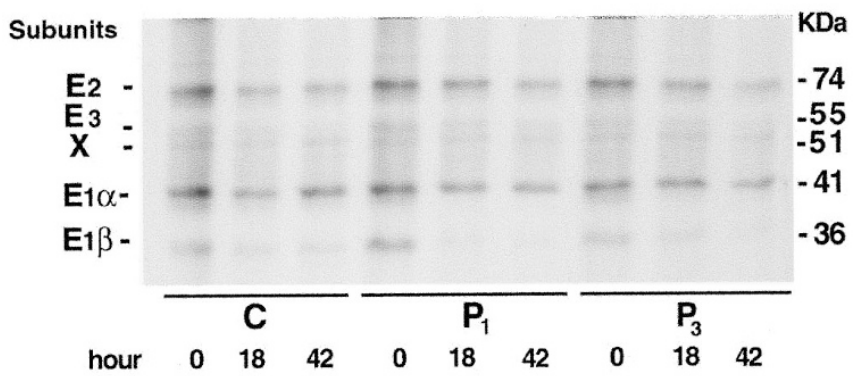

B

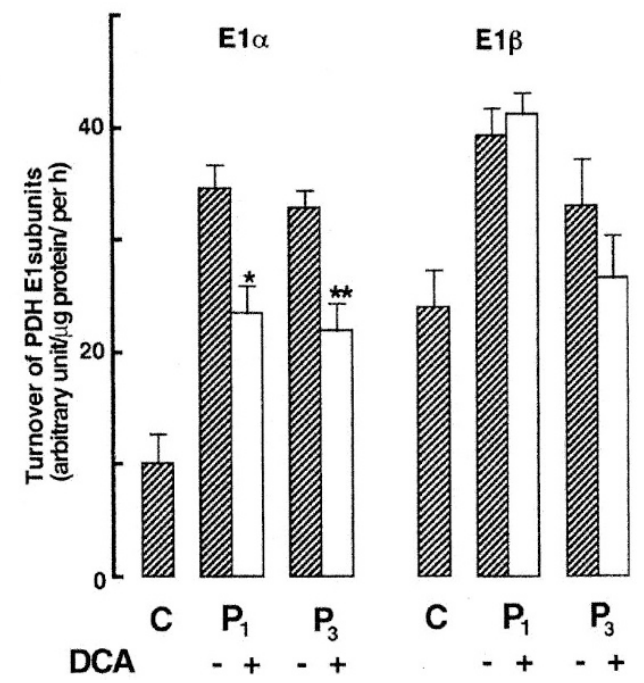

Figure 4. Pulse-chase analysis of PDHC components from fibroblast cell lines of control $(C)$ and patients 1 and $3(P 1, P 3)$ : effect of DCA treatment. $A$, fibroblast proteins from the control and patients 1 and 3 were pulse-labeled with $\left[{ }^{35} \mathrm{~S}\right]$ methionine for $6 \mathrm{~h}$ and chased for 18 and $42 \mathrm{~h}$ in medium without radioactive methionine. Immunoprecipitation and electrophoresis were performed as described in the text. $B,\left[{ }^{35} \mathrm{~S}\right]$ methionine pulse-chase measurement of the effect of DCA $(\square)$ on the relative turnover rate of E1 $\alpha$ and $\beta$ subunits of PDHC from fibroblast cell lines of patients 1 and 3. The effects of DCA treatment on PDHC subunit turnover rate was calculated by measuring the loss of $\left[{ }^{35} \mathrm{~S}\right]$ methionine-labeled peptide during the 42 -h cold chase period, mean \pm SEM in 4-5 independent experiments. Asterisks indicate results significantly different from those for untreated cells. ${ }^{*} p<0.002 ; * * p<0.01$.
36-kD (E1 $\beta$ ) bands after $2 \mathrm{~h}$, and the amounts of radiolabeled PDHC components were maximal after a 6 -h pulse period (data not shown).

To estimate the turnover of the PDHC, fibroblasts from the control and patients were pulse-labeled for $6 \mathrm{~h}$ and chased for various times. In the control, the intensity of the signal for radiolabeled E2 and E1 $\beta$ declined by approximately 53 and $58 \%$, respectively, during the subsequent $42 \mathrm{~h}$; the abundance of radiolabeled $\mathrm{E} 1 \alpha$ and $\mathrm{X}$ proteins declined by approximately $25 \%$ during the same period, indicating that these components were more stable (Fig. 4A).

Fibroblast lysates from patients 1 and 3 displayed normal levels of radiolabeled components after a 6-h incubation with $\left[{ }^{35} \mathrm{~S}\right]$ methionine, indicating that the initial synthesis of the PDHC components, and particularly of E1 $\alpha$ subunits, was normal. The chase study in the cell lines from patients 1 and 3 revealed that the amount of radioactivity in the mutant E1 $\alpha$ subunits decreased during $42 \mathrm{~h}$, to approximately $70 \%$ of that observed during this same period for control E1 $\alpha$ levels ( $p<$ 0.003 and $p<0.02$ ) for both mutant cell lines. The amount of radioactivity in E1 $\beta$ also decreased more rapidly (approximately $40 \%$ ) than that of the control for mutant cell lines. The amount of radioactivity in E2 and $\mathrm{X}$ proteins were unchanged for both mutant cell lines compared with the controls. Chronic DCA treatment reduced the turnover of the E1 $\alpha$ subunit in both mutant cells by approximately $50 \%$. We observed no significant effect on the other PDHC components, in particular for E1 $\beta$ (Fig. $4 B$ ).

Chronic DCA treatment and flux through the PDHC reaction. Digitonin-permeabilized fibroblasts were incubated in a respiratory medium with $1 \mathrm{mM}\left[1-{ }^{14} \mathrm{C}\right]$ pyruvate to measure PDHC activity in intact mitochondrial membranes. L-Carnitine was added in the medium to trap the acetyl CoA produced and prevent feedback inhibition of PDHC.

The two cell lines (from patients 1 and 3) with the largest increases in PDHC activity after DCA treatment were chosen for the study. In untreated fibroblast cell lines, ${ }^{14} \mathrm{CO}_{2}$ production from $\left[1-{ }^{14} \mathrm{C}\right]$ pyruvate was impaired (Fig. 5). But in terms of nanomoles of ${ }^{14} \mathrm{CO}_{2}$ produced per minute per milligram of protein, pyruvate oxidation was higher in permeabilized cells (control values, $6.57 \pm 0.78, n=15$ ) than the activity of the PDH complex previously measured in fibroblast homogenates. In cell lines from patients 1 and 3 , respectively, ${ }^{14} \mathrm{CO}_{2}$ production before DCA treatment was 36 and $49 \%$ compared with the control mean and reached $49 \%$ and $62 \%$ after $3 \mathrm{~d}$ of $5 \mathrm{mM}$ DCA treatment.

Decarboxylation of $\left[1,4-{ }^{14} \mathrm{C}\right]$ succinate was not impaired in the PDHC-deficient cell lines and was not altered by DCA treatment.

\section{DISCUSSION}

Increases in substrate flux to mitochondria and decreases in lactate levels as a result of stimulation of the PDHC have been put forward as mechanisms to account for the beneficial effects of DCA in patients with hyperlactatemia.

DCA is thought to stimulate PDHC activity by inhibiting pyruvate dehydrogenase kinase, thereby locking PDHC in its 


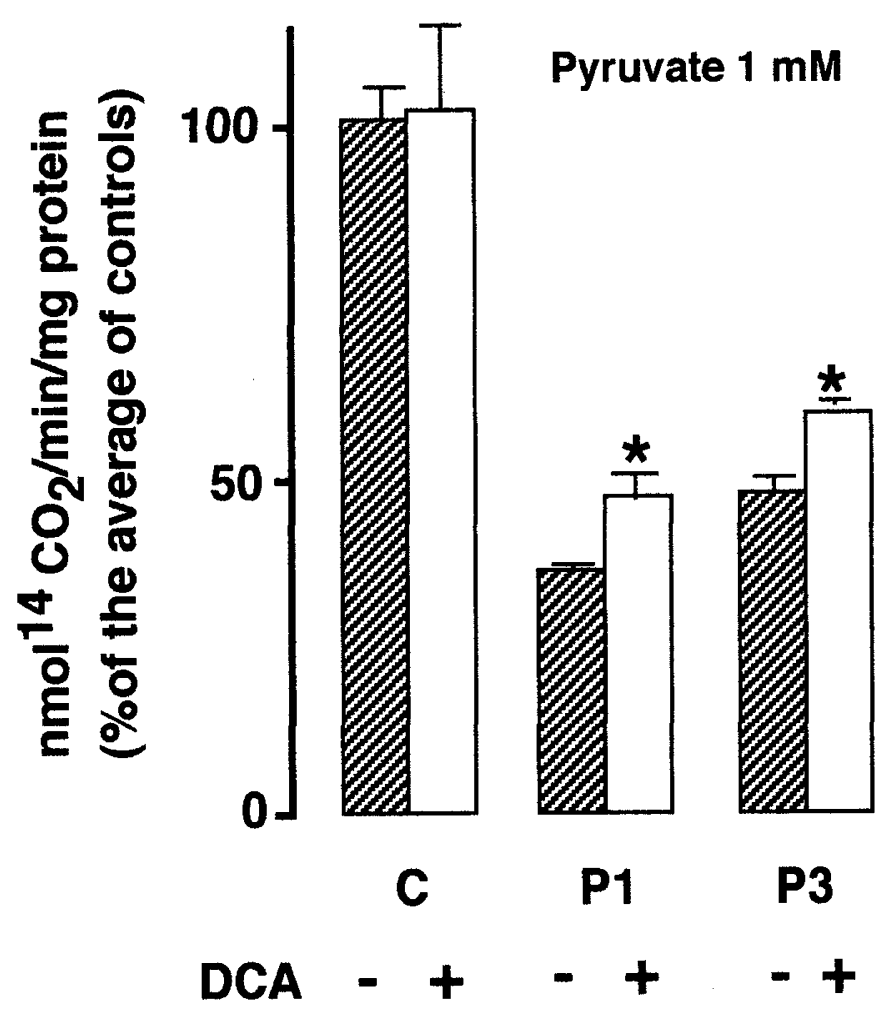

Figure 5. Oxidative decarboxylation rates in digitonin-permeabilized fibroblasts from the control $(C)$ and patients 1 and $3(P 1, P 3)$ : effect of DCA treatment. Fibroblasts from the control and patients were cultured in the culture medium with $5 \mathrm{mM}$ DCA $(\square)$ for $3 \mathrm{~d}$. On d 3, oxidative decarboxylation rates were determined as described in "Methods." Pretreatment oxidative decarboxylation rates, in the absence of DCA (级), were $7.27 \pm 0.35,2.37 \pm 0.08$, and $3.26 \pm 0.17 \mathrm{nmol} \mathrm{CO}_{2} \cdot \mathrm{min}^{-1} \cdot \mathrm{mg}$ protein ${ }^{-1}$ (at $1 \mathrm{mM}$ pyruvate), respectively, for $\mathrm{C}, \mathrm{P} 1$, and $\mathrm{P} 3$. The results, expressed as percent of controls, are the means of triplicate determinations in four separate experiments. Asterisks indicate results significantly different from those for untreated cells. ${ }^{*} p<0.02$.

unphosphorylated, catalytically active form. This short-term effect occurs within $15 \mathrm{~min}$ of incubation of fibroblasts with 5 mM DCA (22). An additional increase in maximal extractable PDHC activity has also been observed in fibroblasts after 3-5 $\mathrm{d}$ of $5 \mathrm{mM}$ DCA supplementation $(14,23)$. This long-term effect was attributed to a decrease of PDHC E1 $\alpha$ subunit degradation, as demonstrated by pulse-chase experiments in control fibroblasts (13). An increase in maximal extractable PDHC activity has also been reported in PDHC-deficient fibroblasts, but the stabilizing effect of chronic DCA treatment was shown to be dependent on the nature of E1 $\alpha$ subunit mutations (14): the activity of PDHC was increased in three PDHC-deficient cell lines with PDHC E1 $\alpha$ mutations associated with decreased polypeptide stability [mutants R141Q, $\mathrm{R} 378 \mathrm{H}$, and $\mathrm{K} 387(\mathrm{fs})]$, whereas no change was observed in a cell line with a catalytically inactive E1 $\alpha$ subunit (mutant R302C).

Our work confirms the selective sensitivity of PDHCdeficient cell lines to DCA treatment. Of the three PDHCdeficient cell lines with PDHC E1 $\alpha$ mutations associated with both a strong decrease in PDHC activity and a decrease in polypeptide stability tested, only two were sensitive to chronic DCA treatment: these two sensitive cell lines presented muta- tions resulting in the replacement of an arginine with a cysteine. The cysteine might facilitate the formation of disulfide bridges, destabilizing the protein. The W383 del mutant cell line was insensitive to DCA treatment. This is probably linked to the 8-bp deletion responsible for the production of small amounts of a poorly functional truncated protein that could not be stabilized by DCA.

Immunoblot analysis identified two cases [patient 1 (R378C mutant) and patient 3 (R88C mutant)] with low steady-state levels of both immunoreactive E1 $\alpha$ and E1 $\beta$, suggesting that the mutant $\mathrm{E} 1 \alpha$ protein may be affected not only in its folding but also in the formation of a stable $\alpha 2 \beta 2$ tetramer. Conversely, in the cell line from patient 2 (W383 del mutant), the steady-state levels of the two E1 subunits were different, consistent with previously reported cases, in which a variable rate of degradation of the $\mathrm{E} 1 \beta$ subunit and an almost constant rate of E1 $\alpha$ subunit degradation were demonstrated by pulsechase experiments $(6,7)$. This suggests that E1 $\beta$ subunit stability depends on the nature of the E1 $\alpha$ subunit gene mutation rather than on the stability of the mutant E1 $\alpha$ subunit. In our cases and in previous reports, defects in the E1 component caused no abnormality of E2 or X in immunoblot analysis.

Radiolabeling studies revealed that the mutant R378C and R88C cell lines produced E1 $\alpha$ and E1 $\beta$ proteins in amounts similar to those produced in control fibroblasts. Pulse-chase experiments clearly demonstrated that E1 $\alpha$ and E1 $\beta$ were degraded more rapidly in fibroblasts from patients than in control fibroblasts. The two mutant cell lines synthesized and processed normally the other subunits (E2 and X). These results are consistent with those of Morten et al. (14) for the mutant $\mathrm{R} 378 \mathrm{H}$ cell line, except that PDHC antibodies did not immunoprecipitate the E1 $\beta$ subunit in the conditions used by Morten et al. (14).

The only subunit for which the steady-state level was significantly affected by DCA treatment was E1 $\alpha$. Pulse-chase experiments confirmed that this effect was caused by a decrease in E1 $\alpha$ degradation, without significant effect on steady-state levels of the E1 $\beta$ subunit. These results are also consistent with the results of Morten et al. (14).

We investigated whether chronic DCA treatment improved the metabolic function of $\mathrm{PDHC}$ by measuring ${ }^{14} \mathrm{CO}_{2}$ production from $\left[1-{ }^{14} \mathrm{C}\right]$ pyruvate in digitonin-permeabilized fibroblasts from two patients. Background rates of ${ }^{14} \mathrm{CO}_{2}$ production in permeablized E1 $\alpha$ mutants might appear disproportionate to the severity of reduced $\mathrm{PDHC}$ activity. One explanation could be that part of residual ${ }^{14} \mathrm{CO}_{2}$ production would be caused by $\left[{ }^{14} \mathrm{C}\right]$ oxaloacetate formation by pyruvate carboxylase. But the high ADP to ATP ratio and the trapping of acetyl CoA by L-carnitine in the medium prevent activation of pyruvate carboxylase. Alternatively, it may be argued that the actual consequence of the PDHC defect on pyruvate metabolism is better reflected in permeabilized fibroblasts than in the current assay performed in a cell-free medium. Three days of DCA treatment mildly increased the pyruvate oxidation via the PDHC reaction. It provides further evidence that chronic DCA treatment stimulates PDHC. 
Additional studies in patients, such as the determination of in vivo glucose oxidation rate using stable isotopes combined with the determination of metabolites in the brain by magnetic resonance spectroscopy, might confirm the potential benefit of chronic DCA treatment in patients with DCA-sensitive mutations (24). The occurrence of DCA-sensitive mutations suggests that DCA treatment is potentially useful as an adjuvant to ketogenic diet and vitamin treatment in PDHC-deficient patients. A time-limited clinical trial with oral DCA should be considered in such patients, provided that the diagnosis was made early, before advanced neurologic deterioration, and that DCA efficiency is assessed both clinically and metabolically, with in vitro response to DCA confirmed by further experiments in cultured fibroblasts.

Acknowledgments. The authors thank Prof. J.M. Saudubray, J.M. Pedespan, and Dr. H. Ogier de Baulny from the Pediatric Department [Hôpital Enfants Malades (J.M.S.) and Hôpital Robert Debré (H.O.), Paris, and Hôpital Pellegrin Bordeaux (J.M.P.)] for providing us with the opportunity of working with their patients. We also thank Prof G. Lindsay for his kind gift of polyclonal antibodies against PDHC purified from pig heart. We thank Dr. B. Desbuquois and Dr. F. Authier for critical reading of this manuscript. We also thank Y. Deris for expert artwork.

\section{REFERENCES}

1. Robinson BH 1995 Lactic acidemia (disorders of pyruvate carboxylase, pyruvate dehydrogenase). In: Scriver CR, Beaudet AL, Sly WS, Valle D (eds) The Metabolic and Molecular Bases of Inherited Disease, 7th Ed. McGraw-Hill, New York, pp 1479-1499

2. Patel MS, Roche TE 1990 Molecular biology and biochemistry of pyruvate dehydrogenase complexes. FASEB J 4:3224-3233

3. Marsac C, François D, Fouque F, Benelli C 1999 Pyruvate dehydrogenase deficiencies. In: Lestienne P (ed) Mitochondrial Diseases, Models and Methods. SpringerVerlag, Berlin, pp 174-184

4. Lissens W, deMeirleir L, Seneca S, Liebaers I, Brown GK, Brown RM, Ito M, Naito E, Kuroda Y, Kerr DS, Weler ID, Patel MS, Robinson BH, Seyda A 2000 Mutations in the X-linked pyruvate dehydrogenase (E1) $\alpha$ subunit gene (PDHA1) in patients with a pyruvate dehydrogenase complex deficiency. Hum Mutat 15:209-19
5. Brown RM, Dahl HH, Brown GK 1989 X chromosome localization of the functional gene for the E1 $\alpha$ subunit of the human pyruvate dehydrogenase complex. Genomics $4: 174-181$

6. Mahbubul Huq AHM, Ito M, Naito E, Saijo T, Takeda E, Kuroda Y 1991 Demonstration of an unstable variant of pyruvate dehydrogenase protein (E1) in cultured fibroblasts from a patient with congenital lactic acidosis. Pediatr Res 30:11-14

7. Fujii T, Garcia Alvarez MB, Sheu KFR, Franz-Eble PJ, de Vivo DC 1996 Pyruvate dehydrogenase deficiency: the relation of the E1 $\alpha$ mutation to the E1 $\beta$ subunit deficiency. Pediatr Neurol 14:328-334

8. Otero LJ, Brown RM, Brown GK 1998 Arginine 302 mutations in the pyruvate dehydrogenase $\mathrm{E} 1 \alpha$ subunit gene; identification of further patients and in vitro demonstration of pathogenicity. Hum Mutat 12:114-121

9. Stacpoole PW, Barnes CL, Hurbanis MD, Cannon SL, Kerr DS 1997 Treatment of congenital lactic acidosis with dichloroacetate. Arch Dis Child 77:535-541

10. Evans OB, Stacpoole PW 1982 Prolonged hypolactemia and increased total pyruvate dehydrogenase activity by dichloroacetate. Biochem Pharmacol 31:1295-1300

11. Whitehouse S, Cooper RH, Randle PJ 1974 Mechanism of activation of pyruvate dehydrogenase by dichloroacetate. Biochem J 41:761-774

12. Stacpoole PW 1989 Pharmacology of DCA. Metabolism 38:1124-1144

13. Morten KJ, Caty M, Matthews PM 1998 Stabilization of the pyruvate dehydrogenase E1 $\alpha$ subunit by dichloroacetate. Neurology 51:1331-1335

14. Morten KJ, Beattie P, Brown GK, Matthews PM 1999 Dichloroacetate stabilizes the mutant E1 $\alpha$ subunit in pyruvate dehydrogenase deficiency. Neurology 53:612-616

15. Marsac M, Benelli C, Desguerre I, Diry M, Fouque F, de Meirleir L, Ponsot G, Seneca S, Poggi F, Saudubray JM, Zabot MT, Fontan D, Lissens W 1997 Biochemical and genetic studies of four patients with pyruvate dehydrogenase E1- $\alpha$ deficiency. Hum Genet 99:785-792

16. Geoffroy V, Poggi F, Saudubray JM, Fouque F, Lissens W, Lindsay JG, Sanderson SJ, de Meirleir L, Marsac C, Benelli C 1995 Defect in the X-lipoyl-containing component of the pyruvate dehydrogenase complex in a patient with a neonatal lactic acidemia. Pediatrics 97:267-272

17. Denyer GS, Lam D, Cooney GJ, Caterson ID 1989 Effect of starvation and insulin in vivo on the activity of the pyruvate dehydrogenase complex in rat skeletal muscles. FEBS Lett 250:464-468

18. Bradford MM 1976 A rapid and sensitive method for the quantification of microgram quantities of protein using the principle of protein dye binding. Anal Biochem 72:248-254

19. Lissens W, de Meirleir L, Seneca S, Benelli C, Marsac C, Tien Poll B, Briones P, Ruttenbeck W, Van Diggelen O, Chaigne D, Ramaekers V, Liebaers V 1996 Mutation analysis of the pyruvate dehydrogenase E1 $\alpha$ gene in eight patients with a pyruvate dehydrogenase complex deficiency. Hum Mutat 7:46-51

20. Pande SV, Brivet M, Slama A, Demaugre F, Aufrant C, Saudubray JM 1993 Carnitine-acylcarnitine translocase deficiency with severe hypoglycemia and auriculoventricular block: translocase assay in permeabilized fibroblasts. J Clin Invest 91:1247-1252

21. Trijbels JMF, Sengers RCA, Ruitenbeek W, Fischer JC, Bakkeren JAJM, Janssen AJM 1988 Disorders of the mitochondrial respiratory chain: clinical manifestations and diagnostic approach. Eur J Pediatr 148:92-97

22. Sheu KFR, Hu OWC, Utter MF 1981 Pyruvate dehydrogenase complex activity in normal and deficient fibroblasts. J Clin Invest 67:1463-1471

23. Naito E, Kuroda Y, Takeda E, Yokota I, Kobashi H, Miyao M 1988 Detection of pyruvate metabolism disorders by culture of skin fibroblasts with dichloroacetate. Pediatr Res 23:561-564

24. Schulze A, Mayatepek E, Langhans CD, Bachert P, Ruitenbeek W, Rating D 1998 In vivo methods useful for therapy monitoring in lactic acidosis. J Inherit Metab Dis 21:691-692 